\title{
High strain rate characterization of shock absorbing materials for landmine protection concepts
}

\author{
Jennifer McArthur ${ }^{\mathrm{a}}$, Christopher Salisbury ${ }^{\mathrm{a}}$, Duane Cronin ${ }^{\mathrm{a}}$, Michael Worswick ${ }^{\mathrm{a}}$ and Kevin Williams ${ }^{\mathrm{b}}$ \\ ${ }^{a}$ University of Waterloo, 200 University Ave W., Waterloo, ON, Canada N2L 3G1 \\ Tel.: +1 5198884567 x 2346; E-mail: jmotuz@lagavulin.uwaterloo.ca \\ ${ }^{\mathrm{b}}$ Defence Research Establishment Valcartier, 2459 Pie XI Blvd. Nord, Val Bélair, Quebec, Canada G3J 1X5
}

Received 3 December 2001

Revised 17 October 2002

\begin{abstract}
Numerical modelling of footwear to protect against anti-personnel landmines requires dynamic material properties in the appropriate strain rate regime to accurately simulate material response. Several materials (foamed metals, honeycombs and polymers) are used in existing protective boots, however published data at high strain rates is limited.

Dynamic testing of several materials was performed using Split Hopkinson Pressure Bars (SHPB) of various sizes and materials. The data obtained from these tests has been incorporated into material models to predict the initial stress wave propagation through the materials. Recommendations for the numerical modeling of these materials have also been included.
\end{abstract}

\section{Introduction}

An estimated 110 million landmines are hidden around the world [1], interfering with agriculture as well as industrial development. In 1997, the Ottawa treaty [2] was signed to ban landmines around the world and many nations have responded to this problem with extensive de-mining efforts to decontaminate mine-affected areas.

The design of footwear to protect against landmines is extremely complex and must take into account both the shock waves from the blast and the rapid expansion of the explosive gases immediately below the foot. Experimental testing is limited since it is extremely expensive and requires significant expertise. A method that allows many concepts to be inexpensively compared and ranked prior to the experimental trials is thus desirable. With such a method, many potential concepts may be evaluated and only those that show the most promise would then be tested experimentally. Numerical modelling allows for the evaluation of many concepts at a lower cost. To ensure that numerical mod- els will be realistic, several simpler models have been analysed and validated with experimental results [35]. These models found that the explosive gases expand at speeds as high as $1800 \mathrm{~m} / \mathrm{s}$. Since the footwear must be thin enough for normal motion, the peak strain rates in the material will be very high and thus material properties obtained at these strain rates are desired.

This paper discusses the testing and modeling of various materials that are used in existing protective boots using the Split Hopkinson Bar method. These materials include closed-cell polyethylene foams, open-cell aluminum foams and honeycombs and polyurethane rubber.

\section{Literature review}

\subsection{Material models - shock behaviour}

The LS-DYNA hydrocode contains many material models representing a variety of materials [6]. Ideally, both shock and deviatoric behaviour should be in- 


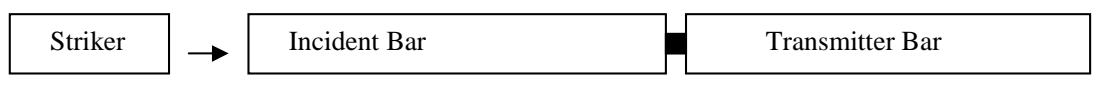

Fig. 1. Set-up of compressive split Hopkinson bar (not to scale).

corporated into the material models. Shock may be accounted for by the use of an equation of state and there are few models that allow this equation of state to be added. The simplest of these models include the null material model which assumes that the material is a viscous fluid and neglects deviatoric properties, the elastic-plastic-hydrodynamic model that assumes the material follows a straight elastic curve to yielding and then may have some strain hardening or softening in the plastic region. Neither accounts for extensive deformation, however and a deviatoric model should be used to determine the long-term deformation of any material.

The linear polynomial equation of state [6] may be used with the data tabulated in LASL shock handbook [7] to describe the shock behaviour.

\subsection{Material models - deviatoric behaviour}

This paper contains stress-strain curves that may be incorporated into deviatoric material models. The following models are recommended for the materials discussed in this report.

\section{Honeycombs and brittle foams}

The honeycomb model [6] uses the solid material properties, densification strain and orthotropic load curves in compression to determine deviatoric behaviour of the material. Isotropic materials such as brittle foams may also use this material model and only two load curves (uniaxial compression and shear) need to be defined in this case.

\section{Nearly incompressible rubber materials (polyureth ane)}

The Mooney-Rivlin rubber model is a two-parameter model for nearly incompressible rubber materials [6]. The input data includes density, Poisson's ratio and a load curve (either force-displacement or stress-strain) which it uses to calculate the two parameters A and B. This model, with an appropriate strain-rate curve at the expected strain rates, has been used for modeling polyurethane rubber response to blast loading with some success [3-5].

\section{Polymer foams}

The simplest foam-specific model is the crushable foam material model [6]. The inputs for this model are the initial density of the foam and a stress-strain curve at a given strain rate.

\subsection{Split hopkinson bars for testing low-impedance materials}

The Hopkinson Bar is the most commonly used method for testing materials in the strain rate regime of $10^{2}-10^{4} \mathrm{~s}^{-1}$. Only compressive split Hopkinson Bar (CSHB) tests were used.

The CSHB consists of a striker bar, an incident bar and a transmitter bar, shown in Fig. 1. The striker bar is propelled from a gas gun at a desired velocity and impacts the incident bar. A compressive stress wave is imparted into the incident bar and propagates uninterrupted until it reaches the sample. The wave is partially transmitted through the sample into the transmitter bar and the rest is reflected into the incident bar. Strain gauges record the strain-time history of both the incident, reflected and transmitted waves.

Classical analysis of a split Hopkinson Bar requires the following assumptions [8]: (i) the bars must remain elastic throughout the test; (ii) no attenuation or dispersion of the stress waves occur; (iii) the pulse is uniform over the cross-section of the bar and, (iv) the specimen remains in equilibrium throughout the test. These assumptions must be valid in order to apply the classical Hopkinson bar equations (Eqs (1)-(4)) to determine the time histories of stress, strain and strain rate within the specimen.

$$
\begin{aligned}
\dot{\varepsilon}(t) & :=\frac{2 \cdot C_{b}}{L_{s}} \cdot \varepsilon_{r}(t) \\
\sigma(t) & :=\frac{2 \cdot C_{b}}{L_{s}} \cdot \varepsilon_{r}(t) \\
\varepsilon(t) & :=\frac{2 \cdot C_{b}}{L_{s}} \cdot \int_{0}^{t} \varepsilon_{r}(t) d \tau \\
C_{b} & :=\sqrt{\frac{E_{b}}{\rho_{b}}}
\end{aligned}
$$

\section{Experimental methods}

Where $C_{b}$ is the speed of sound inside the bars, $E_{b}$ is the modulus of elasticity of the bars, $\rho_{b}$ is the density of the bars, $A_{b}$ and $A_{s}$ are the cross-sectional areas of 
Table 1

Sample sizes and maximum loading for low-rate material tests

\begin{tabular}{llcc}
\hline Material & Sample size (w x d x l) & Aspect ratio (w:l) & Strain rate \\
\hline $34 \mathrm{~kg} / \mathrm{m}^{3}$ polyethylene foam (HL34) & $10 \mathrm{~cm} \times 10 \mathrm{~cm} \times 10 \mathrm{~cm}$ & $1: 1$ & $0.03 / \mathrm{s}$ \\
$34 \mathrm{~kg} / \mathrm{m}^{3}$ polyethylene foam (LD24) & $10 \mathrm{~cm} \times 10 \mathrm{~cm} \times 3.2 \mathrm{~cm}$ & $1: 3$ & $0.03 / \mathrm{s}$ \\
Polyurethane rubber & $5 \mathrm{~cm} \times 5 \mathrm{~cm} \times 1 \mathrm{~cm}$ & $1: 5$ & $0.01 / \mathrm{s}$ \\
Open-cell Al Foam (7\% density, 10PPI) & $3.8 \mathrm{~cm} \times 3.6 \mathrm{~m} \times 1.2 \mathrm{~cm}$ & $1: 3.170 .01 / \mathrm{s}$ & \\
Open-cell Al Foam (7\% density, 20PPI) & $3.9 \mathrm{~m} \times 3.9 \mathrm{~m} \times 1.3 \mathrm{~cm}$ & $1: 3$ & $0.01 / \mathrm{s}$ \\
Open-cell Al Foam (7\% density, 40PPI) & $3.9 \mathrm{~cm} \times 3.75 \mathrm{~cm} \times 1.3 \mathrm{~cm}$ & $1: 2.95$ & $0.01 / \mathrm{s}$ \\
Open-cell Al Foam (11\% density, 10PPI) & $2.5 \mathrm{~cm} \times 2.2 \mathrm{~cm} \times 1.8 \mathrm{~cm}$ & $1: 1.3$ & $0.01 / \mathrm{s}$ \\
Aluminum Honeycomb ("ACG") & $10 \mathrm{~cm} \times 10 \mathrm{~cm} \times 1.6 \mathrm{~mm}$ & $1: 6.25$ & $0.03 / \mathrm{s}$ \\
Aluminum Honeycomb ("CR-III") & $5 \mathrm{~cm} \times 5 \mathrm{~cm} \times 1.6 \mathrm{~mm}$ & $1: 3.125$ & $0.03 / \mathrm{s}$ \\
\hline
\end{tabular}

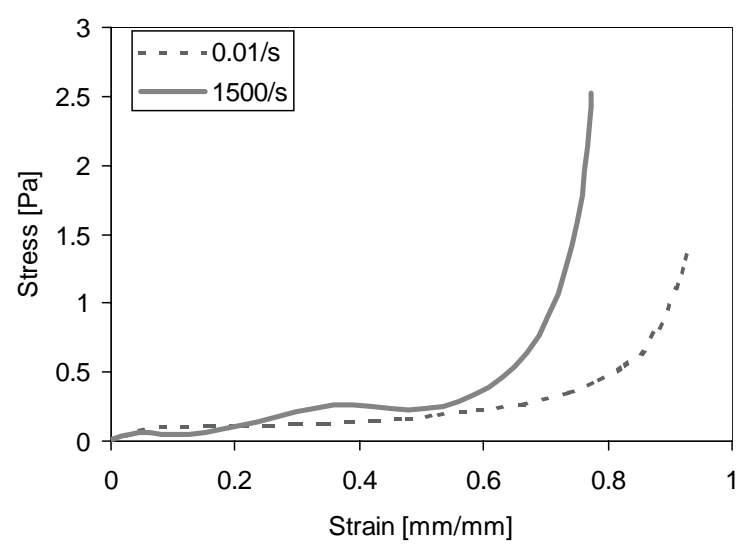

Fig. 2. Stress-strain behaviour of HL34 foam.

the bars and specimen, $L_{s}$ is the length of the specimen and $\varepsilon_{r}$ and $\varepsilon_{t}$ are reflected and transmitted strains.

It should be noted that the real behaviour of the bars is more complex than assumed. Friction must be overcome before a specimen can expand or contract radially. Davies [8] suggests certain criteria for specimen dimensions to minimize this effect. Aspect ratios are very important for ensuring that the friction effects at the ends is minimal [9], and were kept at $\mathrm{L} / \mathrm{D}=1$ for the majority of the materials tested. In order to measure higher strain rates, the aspect ratio of the aluminum foam and honeycomb specimens were as low as $\mathrm{L} / \mathrm{D}=0.25$. This was acceptable because these materials exhibit very low Poisson's ratios (approximately 0.05 [10]) and thus do not deform significantly in the radial direction, so the frictional effects were much less significant than for the other materials.

Polymeric bars require a different approach. Bacon [11] developed an experimental method to correct for the attenuation and dispersion of the wave as it propagates along the length of the bar. The method is based on performing a free end test (where the end of the bar is not restricted) while measuring the incident and reflected wave. Since the bar is allowed to move freely

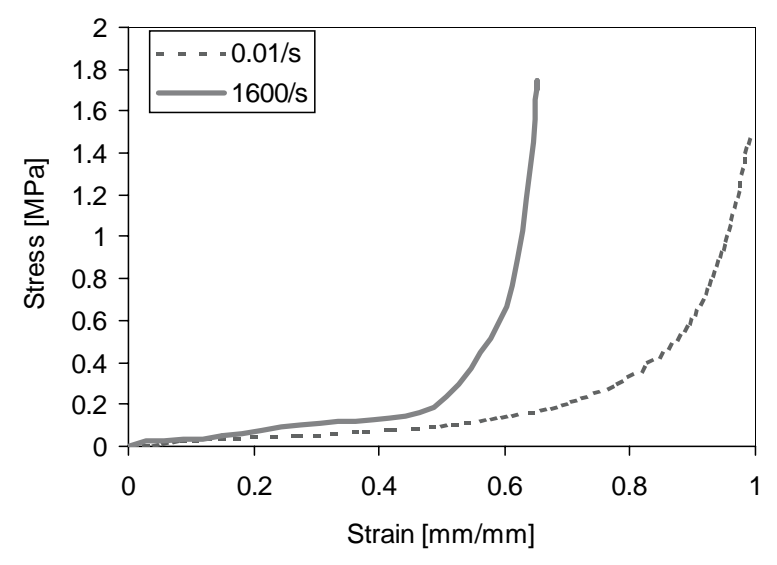

Fig. 3. Stress-strain behaviour of LD24 foam.

at the interface end the entire wave must be reflected. By comparing the difference between the incident and reflected wave a measure of the attenuation and dispersion is possible. This analysis leads to the application of a propagation coefficient (which is a function of frequency) which is comprised of an attenuation coefficient and a wave speed. The impractical nature of performing such calculations in the time domain, lead to the application of spectral methods for determining the propagation coefficients.

Once the free end test has been performed on both the incident and transmitter bars, the application of the propagation coefficient allows the velocity and force time histories at the end of the bars to be determined. The following fundamental relations can then determine the strain rate, strain and stress within the sample [12]:

$$
\begin{aligned}
& \dot{\varepsilon}(t):=\frac{V_{1}(t)-V_{2}(t)}{L_{s}} \\
& \varepsilon(t):=\int_{0}^{t} \dot{\varepsilon}(t) d t \\
& \sigma_{s}:=\frac{F_{2}(t)}{A_{s}}
\end{aligned}
$$




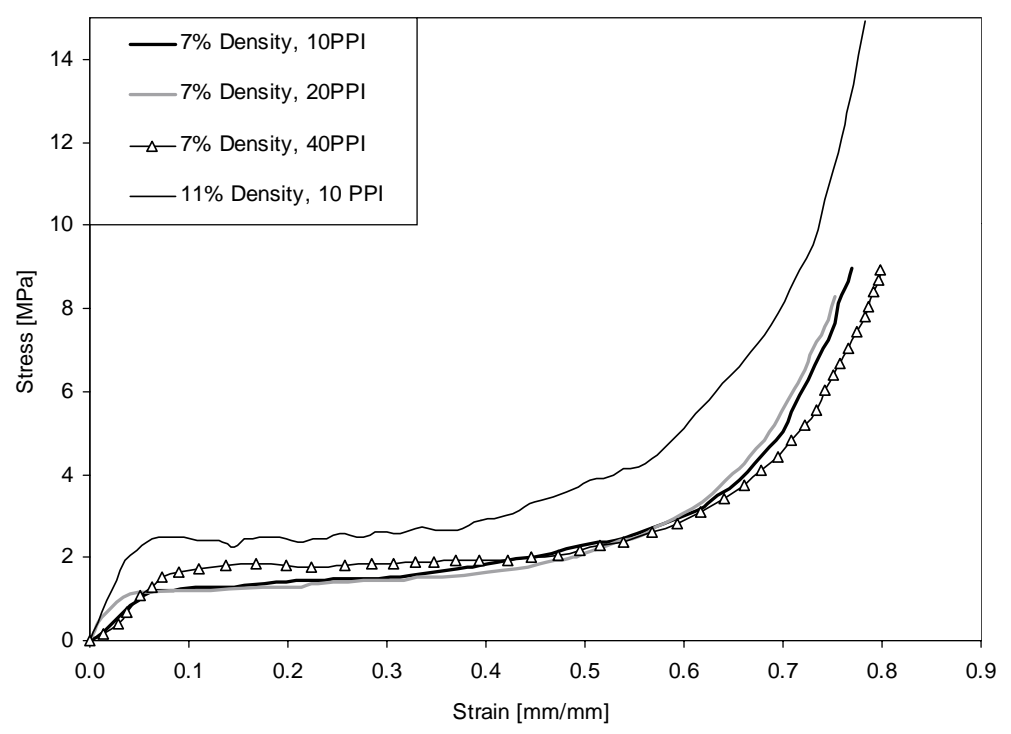

Fig. 4. Low rate $\left(0.01 \mathrm{~s}^{-1}\right)$ stress-strain curves for open-celled aluminum foams.

Where, $L_{s}$ and $A_{s}$ are the same as defined before, $V_{1}$ and $V_{2}$ are the velocities of the end of the incident and transmitter bar at the sample interface and $F_{2}$ is the force in the transmitter bar.

Low strain rate testing of the materials was done using an Instron 4206 machine using steel platens and no lubricant at the ends of the samples. All samples were crushed beyond $90 \%$ engineering strain. The sample sizes were determined according to the material stiffness since the Instron could not accurately test at loads less than $4500 \mathrm{~N}$. Table 1 shows the sample sizes used for each material.

It would have been preferable to test all materials with samples with a 1:1 aspect ratio, however the limitations of minimum load and available material thickness prevented this.

High strain rate testing was done using compressive split Hopkinson bars. Three sets of bars were used to avoid impedance mismatch with the materials. The bars used in these tests included $25.4 \mathrm{~mm}$ diameter aluminum, $25.4 \mathrm{~mm}$ acrylic and $25.4 \mathrm{~mm}$ low-density polyethylene (LDPE). Both the incident and transmitter bars were 96" $(2.4384 \mathrm{~m})$ long for all materials. The striker bars used had various lengths; the aluminum striker was 24 " $(605 \mathrm{~mm})$, the acrylic striker was 28 " $(711 \mathrm{~mm})$ and the LDPE striker was 6" $(150 \mathrm{~mm})$. Table 2 shows the specimen size and bar material(s) for each sample material tested.

The choice of bar is critical to ensure that the impedance is matched as closely as possible between the specimen and the bars. When tested on the acrylic bars, the impedance mismatch between the foam and the bars resulted in a transmitted signal that was too weak to record. With the LDPE bars, however, there was a negligible mismatch since both materials were low-density polyethylene and thus the transmitted signal was much stronger.

\section{Experimental results}

\subsection{Polyethylene foams}

Two polyethylene foams were tested at a range of strain rates: HL34 with density $34 \mathrm{~kg} / \mathrm{m}^{3}$ and LD24 with density $24 \mathrm{~kg} / \mathrm{m}^{3}$. Strain rates from 0.03 to $1500 / \mathrm{s}$ were achieved using the Instron 4026 and $25.4 \mathrm{~mm}$ diameter low-density polyethylene Split Hopkinson Bars respectively. Data obtained from these tests is shown in Figs 2 and 3.

At low strain rates, both polymers had similar behaviour though the LD24 had a lower yield strength and modulus (as expected for a foam of lower density). After the initial elastic loading, there was a significant amount of crushing at nearly constant stress until the stress increased dramatically at densification. The HL34 foam had a higher yield stress and exhibited more energy dissipation than the LD24 foam due to its higher density.

These foams show significant strain-rate dependence, in line with the observations of other researchers [13,14]. Gibson and Ashby [13] determined 
Table 2

Sample sizes, Hopkinson bars used, and achieved strain rates for high-rate material tests

\begin{tabular}{|c|c|c|c|}
\hline Material & Bar material & Sample sizes & Strain rates achieved \\
\hline $34 \mathrm{~kg} / \mathrm{m}^{3}$ polyethylene foam (HL34) & LDPE & $\begin{array}{l}12.7 \mathrm{~mm} \text { diameter } \times 12.7 \mathrm{~mm} \text { tall } 6 \mathrm{~mm} \\
\text { diameter } \times 6 \mathrm{~mm} \text { tall }\end{array}$ & $1500 / \mathrm{s}$ \\
\hline $34 \mathrm{~kg} / \mathrm{m}^{3}$ polyethylene foam (LD24) & LDPE & $\begin{array}{l}12.7 \mathrm{~mm} \text { diameter } \times 12.7 \mathrm{~mm} \text { tall } 6 \mathrm{~mm} \\
\text { diameter } \times 6 \mathrm{~mm} \text { tall }\end{array}$ & $1600 / \mathrm{s}$ \\
\hline Polyurethane rubber & Acrylic and aluminum & $\begin{array}{l}12.7 \mathrm{~mm} \text { diameter } \times 12.7 \mathrm{~mm} \text { tall } 6 \mathrm{~mm} \\
\text { diameter } \times 6 \mathrm{~mm} \text { tall }\end{array}$ & $3000 / \mathrm{s}$ \\
\hline Open-cell Al Foam (7\% density, 10PPI) & Acrylic & $\begin{array}{l}12.7 \mathrm{~mm} \text { diameter } \times 12.7 \mathrm{~mm} \text { tall } 12.7 \mathrm{~mm} \\
\text { diameter } \times 6 \mathrm{~mm} \text { tall }\end{array}$ & $1800 / \mathrm{s}$ \\
\hline Open-cell Al Foam (7\% density, 20PPI) & Acrylic & $12.7 \mathrm{~mm}$ diameter $\times 12.7 \mathrm{~mm}$ tall & $1200 / \mathrm{s}$ \\
\hline Open-cell Al Foam (7\% density, 40PPI) & Acrylic & $12.7 \mathrm{~mm}$ diameter $\times 12.7 \mathrm{~mm}$ tall & $2200 / \mathrm{s}$ \\
\hline Open-cell Al Foam (11\% density, 10PPI) & Acrylic & $\begin{array}{l}12.7 \mathrm{~mm} \text { diameter } \times 12.7 \mathrm{~mm} \text { tall } 12.7 \mathrm{~mm} \\
\text { diameter } \times 6 \mathrm{~mm} \text { tall } 12.7 \mathrm{~mm} \text { diameter } \times \\
3 \mathrm{~mm} \text { tall }\end{array}$ & $1500 / \mathrm{s}$ \\
\hline Aluminum Honeycomb (“ACG”) & Acrylic & 7 -cell cluster $\times 1.6 \mathrm{~mm}, 8 \mathrm{~mm}$ tall & $2400 / \mathrm{s}$ \\
\hline Aluminum honeycomb (“CR-III") & Acrylic & 7 -cell cluster $\times 1.8 \mathrm{~mm}, 9 \mathrm{~mm}$ tall & $1400 / \mathrm{s}$ \\
\hline
\end{tabular}

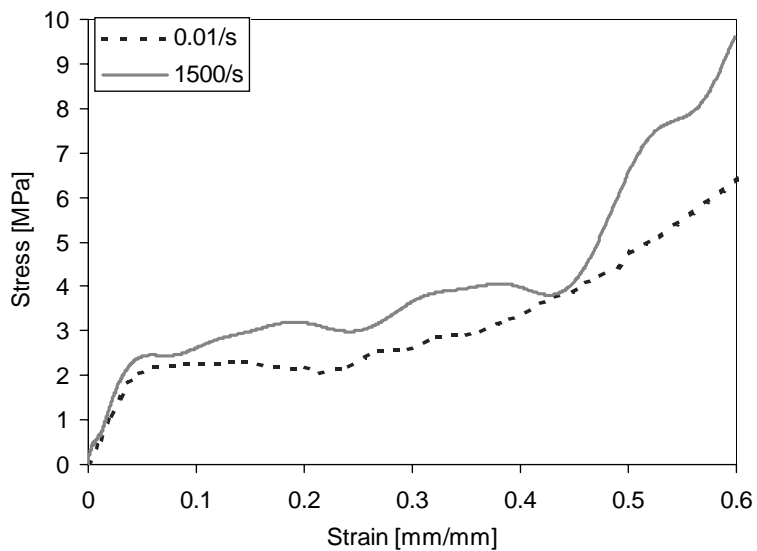

Fig. 5. Behaviour of 11\%, 10PPI Duocel foam.

that the compression of the fluid within the cells (air, in this case) is very rate-dependent and that this is the governing behaviour for foams of this density.

\subsection{Open-celled foamed aluminum}

Foamed aluminum is available in two forms: opencelled, with lamellae rather than solid cell walls, and closed-cell foams. Open-celled foams are widely used in crumple zones for cars [15] and other energyabsorption applications due to their crush strength and negligible strain-rate sensitivity at moderate strain rates $\left(<1200 \mathrm{~s}^{-1}\right)$.

Several varieties of Duocel open-celled aluminum foams were tested: $7 \%$ relative density with 10,20 and 40 pores per inch, and $11 \%$ relative density with 10 pores per inch. Low-rate tests were conducted at a strain rate of approximately $0.01 / \mathrm{s}$. Figure 4 compares these results.

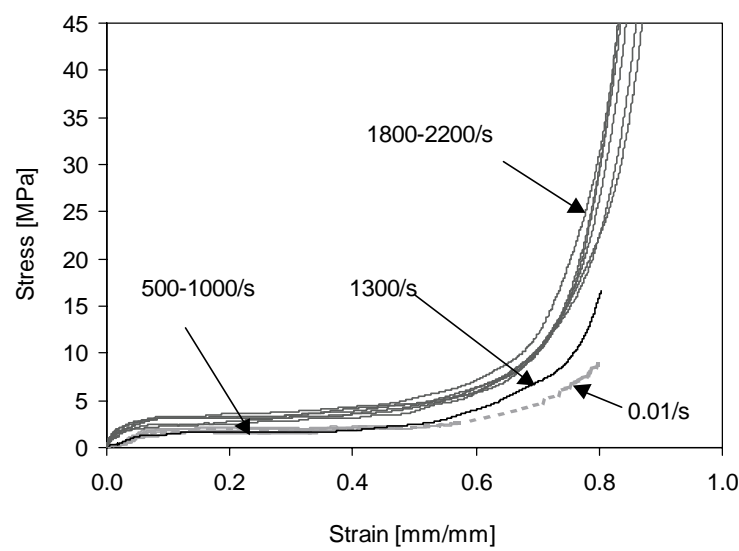

Fig. 6. Behaviour of 7\%, 40PPI Duocel foam.

Note that, at this rate, the relative density has a much larger effect on the foam behaviour than the size of the pores. Since there is much more metal in a higher density foam, it logically follows that the area of metal in a given cross-section will be larger (regardless of pore size) and thus the material will be stronger as density increases. Other researchers have found that this is generally true for aluminum foams [13], and specifically for Duocel open-celled foams [15].

In order to properly represent the material, sample sizes were chosen such that each dimension included at least 10 cells. An exception was made for the 10PPI specimens, which had only 5 cells in each direction due to the maximum allowable specimen size for the bars. Due to these limitations, strain rates were limited to $1500 / \mathrm{s}$ for the 10PPI foams and 2200/s for the 40PPI foams. The results suggest that this was an acceptable specimen size since the stress-strain curves obtained were consistent with the trends observed by 


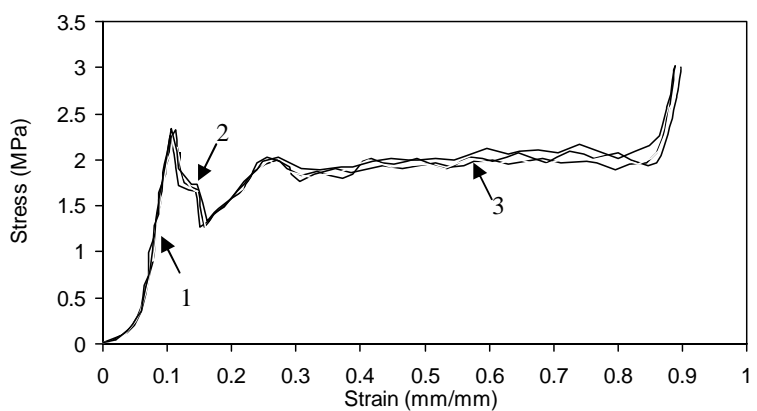

Fig. 7. Low rate out-of-plane stress-strain curves for ACG Aluminum honeycomb.

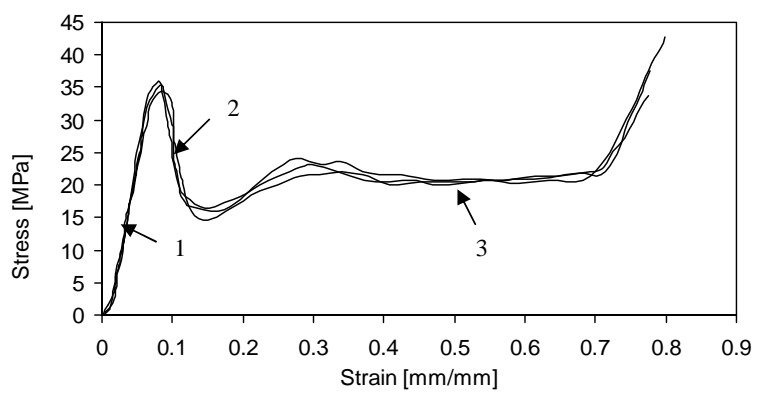

Fig. 8. Low rate out-of-plane stress-strain curves for CR-III Aluminum honeycomb.

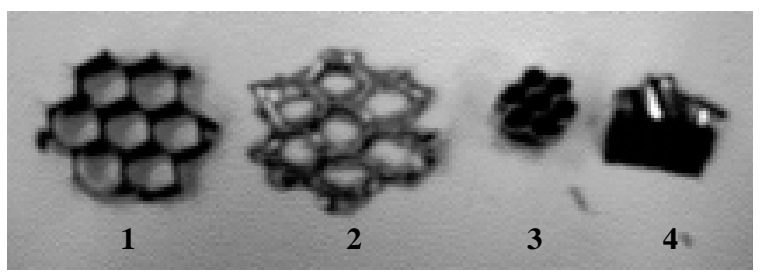

Fig. 9. Honeycomb specimens for dynamic testing ACG before (1) and after (2), CR-III before (3) after (4).

Danneman [16] for 40PPI Duocel aluminum foam and Deshpande [17] for 20PPI Duocel aluminum foam.

Dynamic tests of these materials show very similar results at strain rates lower than $1500 \mathrm{~s}^{-1}$ in $11 \%$ relative density, 10PPI (Fig. 5) and less than $1300 \mathrm{~s}^{-1}$ for $7 \%$ relative density, 40PPI foam (Fig. 6).

Danneman [16] suggested that strain rate effects are negligible up to $1200 / \mathrm{s}$ strain rate for the 40PPI foam and this is confirmed by the data obtained. At strain rates higher than $1300 \mathrm{~s}^{-1}$, a strain rate dependence is seen at strains above $50 \%$, though this may be related to the specimen size. Further high-strain rate tests should be done with these materials using bars capable of higher firing pressures so that the same specimen sizes may be used for all tests. A definite strain rate

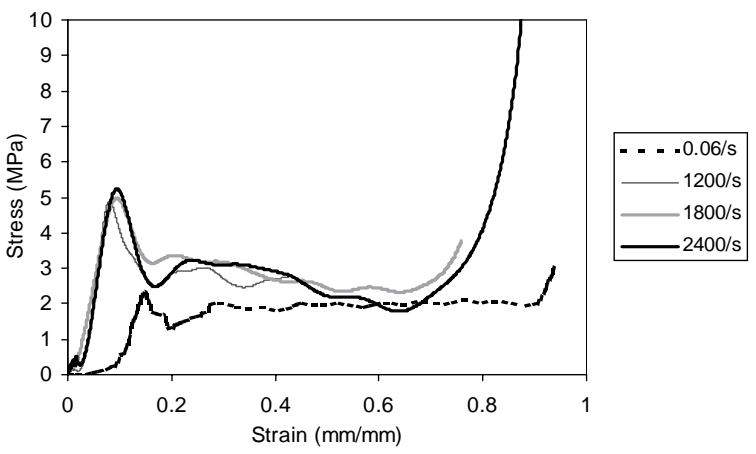

Fig. 10. Out-of-plane stress-strain curves for ACG Aluminum Honeycomb.

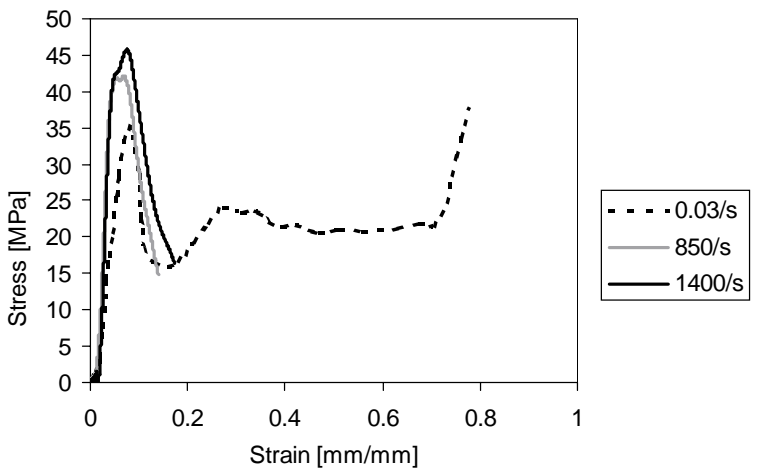

Fig. 11. Out-of-plane stress-strain curves for CR-III Aluminum Honeycomb.

effect is seen at strain rates exceeding $1500 \mathrm{~s}^{-1}$ for the 40PPI foam. Deshpande [17] suggested that there was little strain rate sensitivity until 5000/s, but that conclusion was based on a 20PPI foam. It is possible that the reduced pore size in the 40PPI foam increases the strain rate effect because the cell walls are much closer together, thus the foam behaves more like solid aluminum in this regime.

\subsection{Honeycombed aluminum}

Honeycombed materials are used in a variety of applications, most often as an energy absorbing material. Its strength is much higher out-of-plane and it crushes in three modes of deformation [13]: linear elastic loading (1), plastic buckling (2), and crushing (3), as shown in Figs 7 and 8. Two types of honeycomb were tested: ACG (ACG-1/4-4.8) and CR-III (CRIII-1/85052-.006N-2.21-STD), both manufactured by Hexcel. These graphs clearly show the three modes of deformation listed above. 

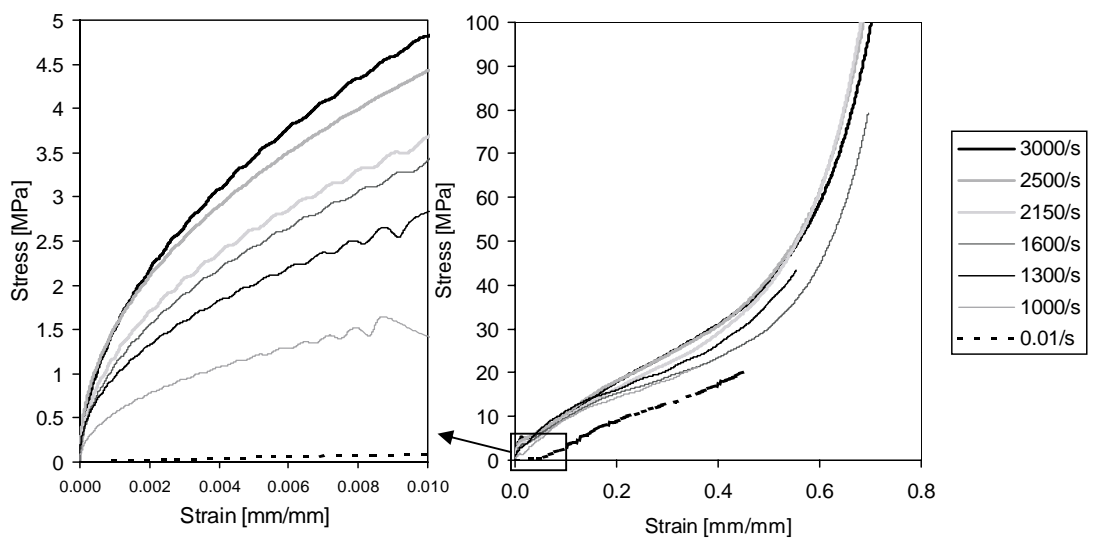

Fig. 12. Stress-strain curves for polyurethane rubber.

Gibson and Ashby [13] calculate the plastic buckling stress $\left(\sigma_{\mathrm{pl}}\right)$ of honeycombs out-of-plane from the yield stress of the solid material $\left(S_{\mathrm{ys}}\right)$, wall thickness $(\mathrm{t})$ and cell wall length (1). Equation (8) applies to honeycomb with single thickness cell walls (such as ACG) and Eq. (9) for honeycombs where two of the six walls are double-thickness (CR-III):

$$
\begin{aligned}
\sigma_{\mathrm{pl}_{\mathrm{i}}} & :=6.6 \cdot\left(\frac{t_{i}}{l_{i}}\right)^{\frac{5}{3}} \cdot S_{\mathrm{ys}} \\
\sigma_{\mathrm{pl}_{i}} & :=5.6 \cdot\left(\frac{t_{i}}{l_{i}}\right)^{\frac{5}{3}} \cdot S_{\mathrm{ys}}
\end{aligned}
$$

The plastic buckling stresses predicted using these equation are $31 \mathrm{MPa}$ for the CR-III (Eq. (9)) and 2.4 MPa for ACG (Eq. (8)) The experimentally observed values, $35 \mathrm{MPa}$ and $2.3 \mathrm{MPa}$ for CR-III and ACG respectively, compare reasonably well with these predictions.

Dynamic testing was done using a $25.4 \mathrm{~mm}$ diameter aluminum split Hopkinson Bar. The specimens used for this testing consisted of a 7-cell repeated group of the honeycomb, shown in Fig. 9. This specimen shape does not account for the extra energy required to break the adjoining cell walls, thus the data collected from these specimens underestimates the actual strength of the material.

The stress-strain data obtained is shown in Figs 10 and 11.

The CR-III honeycomb shows a reduced strain rate effect, most likely because it tends to fail by shearing at the glued interfaces between the layers, which is not strain rate dependent. It is recommended that larger specimens of the CR-III be tested dynamically to determine whether the mode of failure changes with the number of cells tested.

\subsection{Polyurethane (Elastomer)}

Polyurethane was tested using the $25.4 \mathrm{~mm}$ diameter acrylic and $25.4 \mathrm{~mm}$ aluminum Hopkinson bars. The agreement between both bars was excellent, however only data from the acrylic bar is included in the graphs since the recorded signal was much less noisy. The likely reason for this is that the signal in the aluminum transmitter bar was much weaker than that in the acrylic transmitter bar, thus the noise was much larger with respect to the signal. Figure 12 shows the strain-rate sensitivity at all strain rates tested, with the behaviour at low strains enlarged.

A clear dependence on strain rate is seen at low strains, similar to the results obtained by Yang et al [18]. At higher strains, however, this dependence is not seen as clearly and the curves for strain rates of 1000-3000s1 do not show a direct dependence on strain rate at high strains.

\section{Conclusions}

The material testing presented here included high and low strain rate testing of polymer foams, foamed aluminum, aluminum honeycomb, and polyurethane rubber. The polymer foams were found to be very strain-rate dependent, comparable with results from Gibson and Ashby and Zhao [13,14]. The foamed aluminum tests showed two things: first, that the density has a much more significant effect than cell density at all strain rates, and second, that there is little strain rate sensitivity in the $10^{-2}$ to $10^{3}$ strain rate regime. This observation has been noted by other researchers [16, 17]. The aluminum honeycomb was found to be strainrate dependent, though there was little published data 
to compare these results with. The polyurethane rubber showed a clear strain-rate dependence at low strains, however at higher strains, the strain rate effect in the 1000-3000s-1 regime was not clear.

The deviatoric models discussed in the literature review should be used with the high strain rate data provided in this paper to model the long-term deviatoric behaviour of the materials.

\section{Acknowledgements}

Financial support for this research from the Defence Research and Development Valcartier (DRDV) and Suffield (DRDS), Materials and Manufacturing Ontario (MMO), the Canadian Centre for Mine Action Technologies (CCMAT), National Science and Engineering Research Council (NSERC) and Med-Eng Systems, Inc. is gratefully acknowledged.

\section{References}

[1] US. State Department: http://www.state.gov/www/global/ arms/rpt_9809_demine_nxa.html.

[2] International Campaign to Ban Landmines: http://www.icbl. org/treaty/treatyenglish.pdf.

[3] J. Motuz, D. Cronin, M. Worswick, K. Williams, D. Bourget, and G. Pageau, Numerical Modeling of a Simplified Leg Subject to an Anti-Personnel Blast Mine, 19th Intl Symposium of Ballistics, Interlaken, 2001.

[4] D.S. Cronin, M.J. Worswick and R.J. Pick, DREV Simplified Physical Leg Model: Phase I Literature review and preliminary numerical analysis, W7701-9-1941, 2000.

[5] D.S. Cronin, C. Salisbury, M.J. Worswick, R.J. Pick, K.V.
Williams and D. Bourget, Appropriate Material Selection for Surrogate Leg Models Subjected to Blast Loading, Explomet 2000, Albuquerque, New Mexico.

[6] Hallquist, O. John, LS-DYNA Theoretical Manual, Livermore Software Technology Corp., Livermore, 1998.

[7] Marsh, P. Stanley ed., LASL Shock Hugoniot Data, University of California Press, Berkley, 1980.

[8] R.M. Davies, A critical study of the Hopkinson pressure bar, Philosophical Transactions Royal Society London, Series A A240 (1948), 375-475.

[9] P. Verleysen and J. Degrieck, Non-homogeneous and multiaxial stress distribution in concrete specimens during split Hopkinson tensile tests, Computers and Structures 77 (2000), 669-676.

[10] G. Gioux, T.M. McCormack, L.J. Gibson, Failure of aluminum foams under multiaxial loads, International Journal of Mechanical Sciences 42 (2000), 1097-1117.

[11] C. Bacon, An experimental method for considering dispersion and attenuation in a viscoelastic Hopkinson bar, Experimental Mechanics 38 (1998), 242-249.

[12] C. Salisbury, Spectral Analysis of Wave Propagation through a Polymer Hopkinson Bar, M.A.Sc. Thesis, University of Waterloo, 2001.

[13] Gibson, J. Lorna and Ashby, F. Michael, Cellular Solids Structure and Properties, Pergamon Press, 1988.

[14] H. Zhao, Testing of polymeric foams at high and medium strain rates, Polymer Testing 15 (1997), 507-516.

[15] E. Andrews, W. Sanders and L.J. Gibson, Compressive and tensile behaviour of aluminum foams, Materials Science and Engineering A270 (1999), 113-124.

[16] K.A. Danneman and J. Lankford Jr., High strain rate compression of closed-cell aluminum foams, Materials Science and Engineering A293 (2000), 157-164.

[17] V.S. Deshpande and N.A. Fleck, High strain rate compressive behaviour of aluminum alloy foams International Journal of Impact Engineering 25 (2000), 277-298.

[18] L.M. Yang, V.T.W. Shin and C.T. Lim, A visco-hyperelastic approach to modeling the constitutive behaviour of rubber, International Journal of Impact Engineering 24 (2000), 54560. 

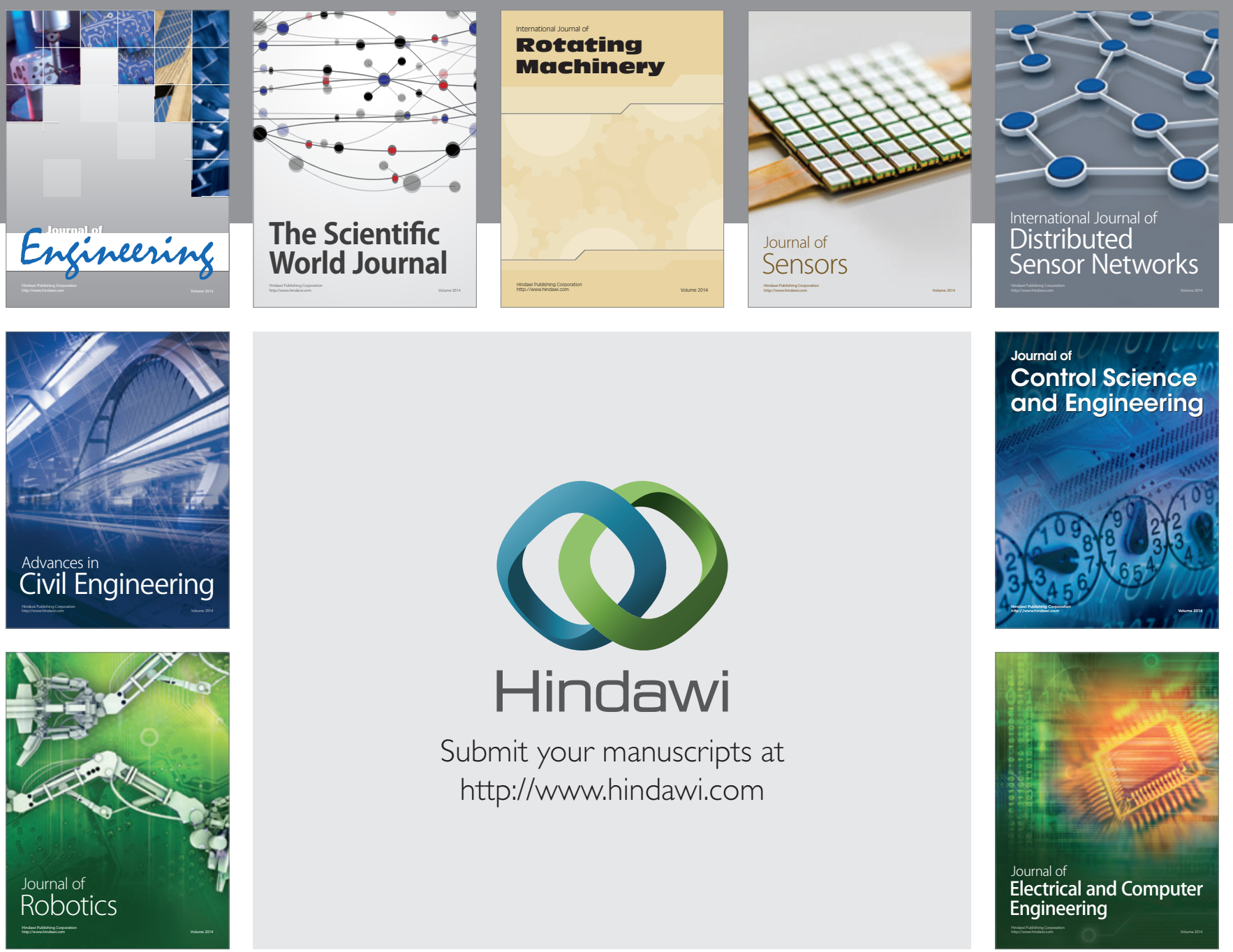

Submit your manuscripts at

http://www.hindawi.com
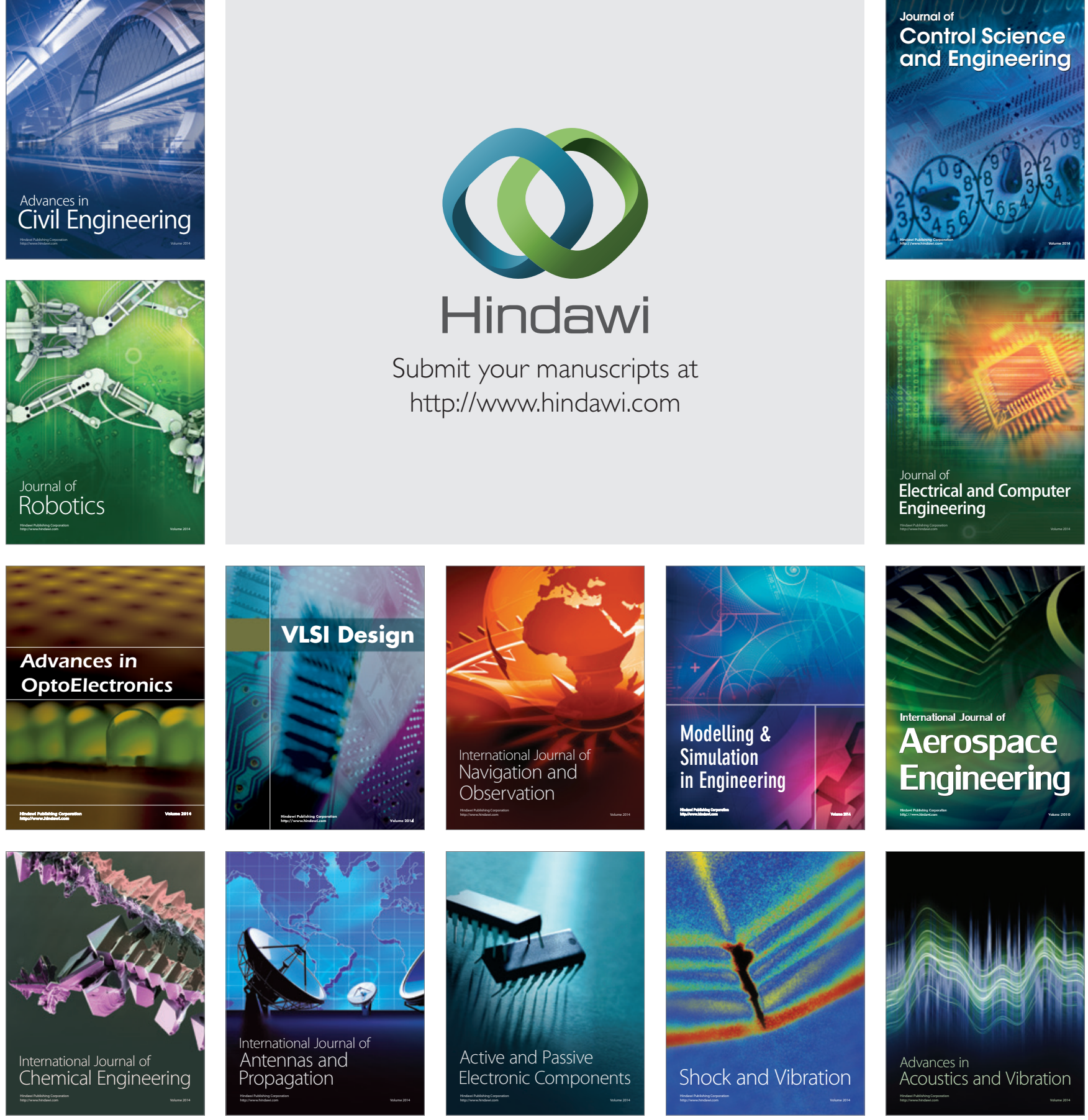